\title{
Investigating the Relationship between Process Management and Organizational Culture: Literature Review and Research Agenda
}

\author{
Corinna Grau ${ }^{1} \&$ Jürgen Moormann ${ }^{1, *}$ \\ ${ }^{1}$ Frankfurt School of Finance \& Management, ProcessLab, Frankfurt a.M., Germany \\ *Corresponding author: Frankfurt School of Finance \& Management, ProcessLab, Sonnemannstrasse 9-11, 60314 \\ Frankfurt a.M., Germany. Tel: 49-154-008-724. E-mail: jmoormann@fs.de
}

Received: December 9, 2013

Accepted: February 17, 2014

Online Published: March 17, 2014

doi:10.5430/mos.v1n2p1

URL: http://dx.doi.org/10.5430/mos.v1n2p1

\begin{abstract}
Managing the business processes of companies is a task which has emerged as a top priority across all industries. However, business process management (BPM) is not just a set of structured methods and technologies which can simply be assigned to employees. On the contrary, the success of any process initiative is interwoven with the culture of the respective company. Additionally, in most cases there is not only one organizational culture but a range of subcultures within the organization due to previous mergers, existing subsidiaries etc. Despite its importance, the interrelation between BPM and organizational culture has been only sparsely explored. This paper analyzes the status quo of academic literature with regard to the interrelation between BPM and organizational culture. The results reveal considerable differences in the perception of the interface between both fields. Furthermore, our analysis reveals that the organizational psychological perspective has been widely neglected in process management literature. To the best of our knowledge, this is the first literature review written from both a process management and an organizational psychological perspective. As such, it strives to contribute to a comprehensive and thorough understanding of this relationship. Based on the review we develop a framework, serving as a basis for a deeper understanding of the interdependency and providing avenues for further research.
\end{abstract}

Keywords: Business Process Management (BPM); organization; organizational culture; organizational psychology

\section{Introduction}

Increasing the performance of a company is the foremost task of every top level manager. In order to achieve the corporate goals business process management (BPM) has emerged as a powerful concept within the last decades. Today, almost all operational excellence programs run in companies all over the world have their roots in the BPM concept. Based on the corporate strategy the business processes are the core of every company and, thus, they build the foundation for all further steps such as the development of information systems and the allocation of human resources. Hence, BPM has become highly relevant for practitioners and management research.

BPM is a multidisciplinary field which, depending on the perception in science and practice, is apprehended in a varying manner. BPM has developed with a strong focus on information technology (IT). However, a limitation solely to an IT-driven approach would not meet the scope of the concept. BPM is also not to be limited to a managerial approach. Rather it includes both aspects and is to be understood as a holistic and distinct research topic (Armistead et al., 1999; Lederer Antonucci \& Goeke, 2011).

Besides the IT-related issues, this holistic perception (Palmberg, 2010) also requires the consideration of many other aspects, such as legal, economic, and organizational facets (Rosemann \& vom Brocke, 2010). In line with this understanding of BPM, organizational culture plays an increasingly important role. A major reason why many process-related projects failed and still fail is the insensitivity concerning the attitude and behavior of the employees involved including the lower and middle management (Cao et al., 2001; Lee \& Dale, 1989). Thus, the consideration of the interrelation is highly relevant for a company's performance.

However, despite an awareness of its importance, the aspect of culture has been only sparsely surveyed in the literature, and is generally solely named among a multitude of other factors (vom Brocke \& Schmiedel, 2011). The 
exact mechanisms of the relationship between culture and BPM have to date been largely unexplored. One reason might be that scientists in the field of BPM adhere to a predominantly IT-driven perception, whereas organizational culture is rather addressed to the research area of organization, management, and organizational psychology.

This paper intends to analyze and determine the status quo of academic literature related to the interrelation between BPM and organizational culture. Therefore, the paper elaborates the overlap between both fields and, by this means, contributes to fill the academic gaps existing today. For this purpose, a comprehensive and transparently documented literature review is carried out.

First, the theoretical basis for this work is constituted in the following section. The methodical approach of the literature review is described in section 3, and in section 4 the results are presented and discussed. In section 5, we develop cornerstones of a research agenda including avenues for further research. The paper ends with a conclusion in section 6 .

\section{Theoretical Background}

In the following, the fundamentals of the two fields - business process management and organizational culture - are briefly described. The theoretical background of both fields serves as an essential basis for a thorough understanding of the interrelationship.

\subsection{Business Process Management}

A multitude of definitions, perceptions, and expectations underlie the concept of BPM. As early as in the 1930s, process orientation was defined as a central orientation for companies (Nordsieck, 1934). Despite this early awareness, the approach was not taken up in practice until the beginning of the 1990s. By means of business process (re-)engineering (BPR), the field won a high degree of attention - supported mainly by the publications of Davenport and Short (1990), Hammer (1990), Davenport (1993), as well as Hammer and Champy (1993).

A business process represents the transformation of an input into the desired output of a company, or any other type of organization. Hence, it describes the flow of material and information within a company (Osterloh \& Frost, 2006). The customer is the initial point of a process-oriented perception. Business processes enable the achievement of corporate objectives, feature interfaces to suppliers and customers, and are composed of a structured succession of cross-functional and cross-organizational value-adding activities (Becker \& Kahn, 2011; Schmelzer \& Sesselmann, 2008).

Even after the BPR hype began to fade, processes and the management of processes have remained the focus of science and practice to this day. On the one hand, today there is hardly any organization that tries to re-invent all of its processes from scratch, according to BPR. On the other hand, only few companies fail to pay attention to the design and management of their processes (Lederer et al., 2011; Voss \& Huxam, 2004). In fact, the main focus now lies on a rather incremental, evolutionary perception of the improvement of processes in companies (Weske, 2007).

Although the term "BPM" serves as an umbrella, the perception of what BPM really is differs widely in practice, as well as in science. The spectrum ranges from a narrow, more technical view to a broad, holistic perspective. At the more technical level, BPM deals with the perspective of single processes or even parts of processes or subprocesses (Dumas et al., 2013). Often, this perspective is associated with the continuous form of improvement. For this purpose, a BPM life cycle is applied. The cycle and its single phases are determined and denominated differently, depending on the author and the respective focus. Hence, despite these differences, the concepts of the BPM life cycle proposed in literature do not differ considerably from each other (Houy et al., 2010). Following authors such as Davenport and Short (1990), van der Aalst et al. (2003), and Kannengiesser (2008), a BPM life cycle typically consists of four to six phases, e.g.: (1) development of a process vision based on the company's strategy, (2) process design encompassing modeling and prototyping the process on various levels, (3) implementation, including execution of the process, (4) monitoring, measurement, and evaluation of the process performance, and (5) process improvement which again has to be aligned to the process vision.

The more technical level is appropriate in terms of e.g., workflow planning, process simulation, process mining, capacity management, and application development. However, from a managerial point of view, the consideration of many other aspects, such as legal, regulatory, competitive, ecological, and psychological facets is required (Hammer \& Champy, 1993; Harmon, 2007; Jeston \& Nelis, 2008; Rosemann \& vom Brocke, 2010). Such a holistic approach strives for effectiveness as well as efficiency of the company, and attempts to align the aforementioned facets with the needs of the customers. Within this comprehensive understanding of BPM, aspects of organizational psychology play a major role in both practice and theory. Therefore, the holistic perspective is indicated when dealing with the 
relation between BPM and cultural issues.

\subsection{Organizational Culture}

The analysis of the interrelation of BPM and organizational culture requires a thorough understanding of the concept of organizational culture itself.

Since the 1930s, the connection between culture and functionality of social organizations has been a highly discussed topic in social sciences. Therefore, culture is seen as an integral criterion for the course of an organization's actions (Mead, 1934; Weber, 1930), and consists of socially conveyed behavior patterns, serving to relate human communities to their environment (Keesing, 1974). Scientists in the field of organizational culture, such as Hofstede (1980, 1991), still relate to this early understanding.

By the turn of the century, the concept of organizational culture became especially popular in terms of the assumption that certain organizational cultures lead to a higher degree of financially measurable business success (Ogbonna \& Harris, 2000). The underlying argument is that the performance of an organization depends on how excessive, i.e., how widely spread in the organization and how strongly supported by employees, the cultural values of the respective organization are (Knapp, 1998; Schein, 1978).

Schein (1990) defines organizational culture as a pattern of basic assumptions discovered or developed within a certain group, while that group learns how to deal with internal and external challenges. If these assumptions prove of value, they are perceived as valid and communicated further to new members of the group.

Schein (1995) explains how and why cultures develop within organizations by describing the need for integration and sense in the actions of the members of the organization. This essential need leads to the evolution of shared elements among the members of an organization, such as shared values, beliefs, and procedures which prove successful and are asserted over time. Such values, beliefs, and procedures are learned by new members of the organization as part of the socialization process. Schein's model of interdependent cultural levels is based on this explanation. Thus, organizational culture can be analyzed on three levels - (1) artifacts, (2) values and norms, and (3) basic assumptions and premises - according to their particular degree of visibility and consciousness (Figure 1).

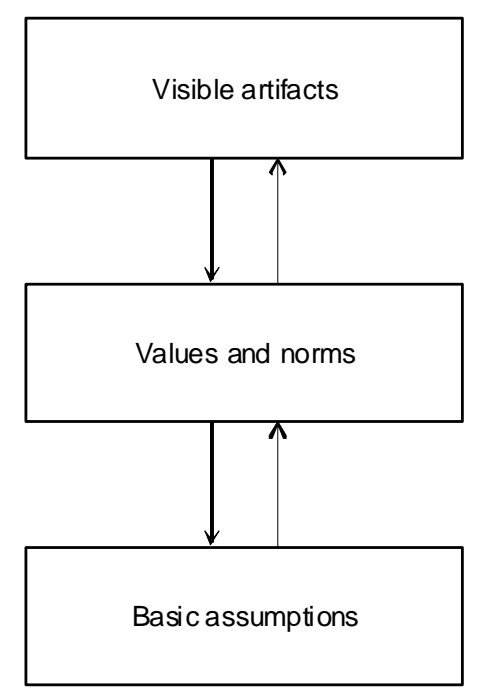

Figure 1. Organizational Culture Model (Schein, 1995, p. 30)

Artifacts, such as cultural phenomena on the surface level, are visible structures and processes in an organization. They are directly observable but are difficult to decipher, and include technologies, symbols, language, and architectures within an organization. The second cultural level consists of shared values and norms. These are the company's strategies and philosophies, which transmit a feeling of what is right and wrong. In this vein, the values serve as an orientation framework that influences the actions of the members within an organization. The third level consists of unconscious and taken-for-granted conceptions and basic assumptions. These premises can be seen as the starting point on which all values and actions are based. With this model and his definition of organizational culture, Schein is the most frequently cited researcher in the field of organizational culture, and his work is fundamental for many scientists in this area (Prätorius \& Tiebler, 1993). 
Overall, it can be assumed that organizational culture is a construct that is shared by the members of the organization and, in this vein, presents a form of affiliation and confraternity (Obenchain, 2002). Thus, the culture of an organization consists of the common prevailing conventions, i.e., the way in which things work within the organization. It represents a sense of identity for the organization's members and carries unexpressed regulations as to how the members of the organization treat each other and how they maintain the social system to which they belong (Cameron \& Quinn, 1999). Organizational cultures are organization-specific and are seen as a rather constant, though not unchangeable factor which has an influence on the relations and operations within an organization (Beugelsdijk et al., 2006).

\section{Methodology of the Literature Review}

It is the objective of the literature review to elaborate the overlap between the fields of BPM and organizational culture, as well as to identify possible academic gaps with regard to this interface from both a process management and an organizational psychological perspective. In addition, a framework is to be developed to conceptualize the interrelation of both fields and their respective influence, and to deliver a basis for further research in this area.

Corresponding to the requirements of such a literature review, this work has to be carried out systematically, and the single steps have to be transparent and replicable (Kitchenham, 2004; Okoli \& Schabram, 2010). For this purpose, the search process and the search results are documented as transparent as possible. To ensure the quality of the literature review, we exclusively focus on papers in scientific, peer-reviewed journals. Papers from other sources, e.g., conference proceedings or gray literature, are therefore excluded.

In line with the approach used by Leyer (2011), the literature review has been carried out in four steps. In the first step, corresponding keywords have been identified in both fields of BPM and organizational culture to represent best the interface between these fields: business process, organization, culture, service management, operation(s), and operational. The search terms business process, organization, and culture have been selected because they directly reflect the two research areas of interest. The search terms operation(s), operational have been selected because they focus on that part of business where the work is actually carried out and the processes are being operated. We also included the search term service management because we found some papers dealing with our topic in the services context while we ran pre-research studies at the beginning of our work. The rather broad spectrum of keywords was deliberately chosen in order not to miss any potentially relevant journal.

In the second step, by means of the keywords identified in the first step, the Genamics JournalSeek database was systematically browsed for relevant academic journals. This database is the most comprehensive freely accessible database for information on scientific journals. It lists all electronically available journals including information on their focus and central topics, and is, thus, well suitable for an extensive literature review. Currently the database contains more than 99500 journal titles (http://journalseek.net/; March 2013); more than 4800 of them are dedicated to business administration. The results of the database research are presented in Table 1.

Table 1. Database Research and Journal Selection Process

\begin{tabular}{lccc}
\hline Search term & $\begin{array}{c}\text { Total number } \\
\text { of journals }\end{array}$ & $\begin{array}{c}\text { Number of } \\
\text { peer-reviewed } \\
\text { journals }\end{array}$ & $\begin{array}{c}\text { Number of selected } \\
\text { journals }\end{array}$ \\
\hline Business process & 4 & 3 & 2 \\
Organization & 85 & 43 & 18 \\
Culture & 256 & 116 & 2 \\
Service management & 14 & 4 & 4 \\
Operation(s), & 91 & 51 & 9 \\
operational & & & $\mathbf{3 5}$ \\
Total number & $\mathbf{4 5 0}$ & $\mathbf{2 1 7}$ & \\
\hline
\end{tabular}

As a result, 217 scholarly journals, whose articles meet the qualitative requirements as being peer-reviewed, were selected. Out of these 217 journals, 35 journals with thematic relevance to the research topic under discussion were identified by carefully proving the declaration of aims and scope of each journal and consulting the editorial board in ambiguous cases. The other journals were not included in the research as they, despite containing some of the relevant keywords, descend from other scientific areas and, thus, were defined as irrelevant with respect to the underlying question. Appendix 1 contains a list of the journals identified as relevant academic, peer-reviewed 
journals. Each journal has been examined over its entire publication period (up to December 2012).

In the third step, the search word combination cultur* and business process was used to conduct further research into the selected journals. This combination was chosen to ensure that the papers identified do in fact deal with both topics.

Subsequently, in the fourth step, each selected journal was browsed by means of the search word combination. Additionally, due to cross references in several of the identified papers, a further article from the Journal of Applied Management Studies, which was thematically cognized as relevant and is also peer-reviewed, was included in the analysis.

The papers identified went through a further selection to prove their relevance with respect to the underlying research topic (Table 2). In the first instance, articles that did not fit the topic of interest, due to not containing thematically relevant content in the abstracts, were removed. The whole text of all remaining papers was worked through thoroughly in regard to the content. The papers whose content was identified as relevant to the underlying question regarding the interrelation between the two fields of BPM and organizational culture were chosen for the study. In this vein, 26 scholarly papers were included in the literature review.

Table 2. Selected Papers of the Literature Review

\begin{tabular}{|c|c|c|}
\hline Author(s) & Year & Title of the paper \\
\hline Ahmad, Francis, \& Zairi & 2007 & $\begin{array}{l}\text { Business process reengineering: critical success factors in higher } \\
\text { education }\end{array}$ \\
\hline Al-Mashari \& Zairi & 1999 & BPR implementation process: an analysis of key success and failure factors \\
\hline Armistead \& Machin & 1997 & Implications of business process management for operations management \\
\hline Armistead \& Machin & 1998 & $\begin{array}{l}\text { Business process management: implications for productivity in } \\
\text { multi-stage service networks }\end{array}$ \\
\hline Baird, Hu, \& Reeve & 2011 & $\begin{array}{l}\text { The relationships between organizational culture, total quality management } \\
\text { practices and operational performance }\end{array}$ \\
\hline Cao, Clarke, \& Lehaney & 2001 & A critique of BPR from a holistic perspective \\
\hline Chen & 1999 & Business Process Management: a thermodynamics perspective \\
\hline Choi \& Chan & 1997 & Business process re-engineering: evocation, elucidation and exploration \\
\hline $\begin{array}{l}\text { Da Silva, Damian, } \\
\text { \& de Pádua }\end{array}$ & 2012 & Process management tasks and barriers: functional to process approach \\
\hline Fagan & 2006 & $\begin{array}{l}\text { Exploring city, county and state e-government initiatives: an East Texas } \\
\text { perspective }\end{array}$ \\
\hline Gulledge \& Sommer & 2002 & Business process management: public sector implications \\
\hline Kohlbacher & 2010 & The effects of process orientation: a literature review \\
\hline Kohlbacher \& Gruenwald & 2011 & Process orientation: conceptualization and measurement \\
\hline Lee \& Dale & 1998 & Business process management: a review and evaluation \\
\hline Lewis & 2002 & Five years on - the organizational culture saga revisited \\
\hline Llewellyn \& Armistead & 2000 & Business process management - Exploring social capital within processes \\
\hline Pritchard \& Armistead & 1999 & Business process management - lessons from European business \\
\hline Ravesteyn \& Batenburg & 2010 & Surveying the critical success factors of BPM-systems implementation \\
\hline Sentanin, Santos, \& Jabbour & 2008 & Business process management in a Brazilian public research centre \\
\hline Sidorova \& Isik & 2010 & Business process research: a cross-disciplinary review \\
\hline $\begin{array}{l}\text { Skrinjar, Bosilj-Vuksic, } \\
\text { \& Indihar-Stemberger }\end{array}$ & 2008 & $\begin{array}{l}\text { The impact of business process orientation on financial and non-financial } \\
\text { performance }\end{array}$ \\
\hline Sundberg \& Sandberg & 2006 & Towards e-government: a survey of problems in organisational processes \\
\hline Telleria, Little, \& MacBryde & 2002 & Managing process through teamwork \\
\hline vom Brocke \& Sinnl & 2011 & $\begin{array}{l}\text { Towards a Conceptualisation of BPM Culture: Results from a Literature } \\
\text { Review }\end{array}$ \\
\hline Zairi & 1997 & $\begin{array}{l}\text { Business process management: a boundaryless approach to modern } \\
\text { competitiveness }\end{array}$ \\
\hline Zucchi \& Edwards & 1999 & $\begin{array}{l}\text { Human resource management aspects of business process management: a } \\
\text { survey }\end{array}$ \\
\hline
\end{tabular}




\section{Academic Papers Addressing the Interrelation between BPM and Organizational Culture}

In this section, the research approaches of the papers selected as being relevant for the literature review are presented. For this purpose, we modified a structure suggested by vom Brocke and Sinnl (2011) and distinguish three main clusters:

1) approaches dealing with the influence of organizational culture on BPM,

2) approaches concerned with the influence of BPM on organizational culture, and

3) approaches claiming the existence of a specific BPM culture.

For an overview of the number of works contributing to the different approaches, see Figure 2.

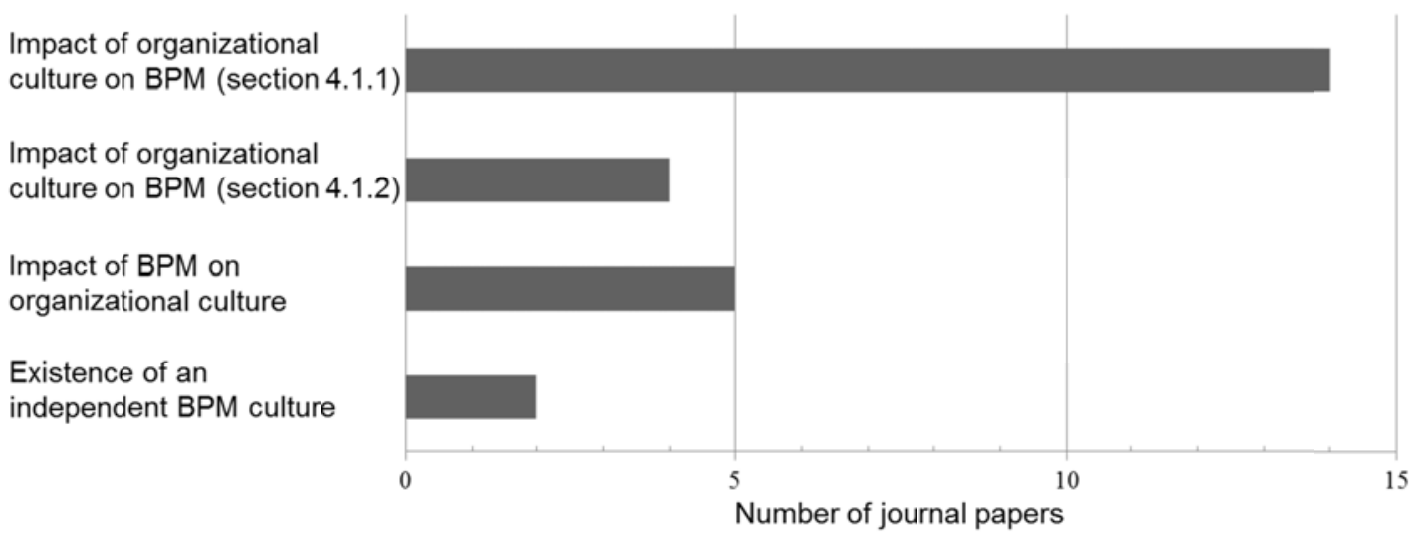

Figure 2. Number of Papers Contributing to the Different Research Approaches

Looking at the timeline, the papers have been published rather equally distributed, with a peak in 1997 till 1999 (9 papers), no paper in the period 2003 till 2005 and another peak in 2010 till 2012 (7 papers).

\subsection{Influence of Organizational Culture on BPM}

The following papers deal with the perception that the culture of an organization has a relevant influence on process management and can be seen as an important context factor in BPM initiatives. With 19 papers in total, this cluster contains the majority of works found in our literature review. Furthermore, we found that the authors deal differently with the influence of organizational psychology: 15 papers specify the influence of organizational culture as a key factor for success or failure in BPM initiatives, whereas four papers do not specify this influence in detail. This difference is crucial as it might help to understand the mechanisms of influence between the two concepts and might add further implications to handle the assumed influence in practice. For this reason, we cover the influence of organizational culture on BPM in two subsections.

\subsubsection{Organizational culture As a Key Factor for Success or Failure}

Most authors focusing on the interrelation between organizational culture and process management conceive culture as a main factor for the success or failure of BPR or BPM initiatives. These papers focus on the implementation phase of the BPM cycle and are briefly presented in the following. The inclusion of papers dealing with BPR initiatives seems to be essential for the literature review, as BPR - being the predecessor of BPM - shows a close conceptual relation to this approach. Also, consideration of works on this topic could provide important leads for the interrelation between BPM and organizational culture, as well as for further research in this field.

Kohlbacher (2010) as well as Kohlbacher and Gruenwald (2011) aim to develop and validate a model for measuring the key dimensions of the construct "process orientation". This term, understood as a comprehensive orientation on BPM as the central management style in an organization or rather the determination of an organization by means of their business processes, is the basis of Kohlbacher and Gruenwald's (2011) approach. In the first instance, the authors develop a priori model on the theoretical dimensions of process orientation and test it empirically. The model is based on the results of a literature review by Kohlbacher (2010) about the influence of process orientation on companies' success. The authors identify seven dimensions of the construct of process orientation. One of these is "a corporate culture in line with the process approach" (Kohlbacher \& Gruenwald, 2011, p. 278). This dimension is composed of employees' customer-oriented attitude: employees' responsibility for the success of the company, the 
existence of teamwork, interaction and communication with regard to processes, the employees' knowledge of process execution, and the effects of process results on subsequent process steps and on the customer. Kohlbacher and Gruenwald (2011) explain that, in terms of obtaining knowledge of how processes are executed, the process approach in an organization is being lived by the employees and, thus, plays an important role for an organizational culture striving for process thinking.

Ravesteyn and Batenburg (2010) also describe cultural aspects as an important element within the scope of BPM. They offer a detailed examination of whether there is a common understanding of process management, and the critical factors of success with respect to the implementation of BPM systems. For this purpose, the authors present a framework for the implementation of BPM systems. One result is the huge importance of different organization-cultural factors, such as communication and involvement of stakeholders, as well as a high resistance of employees when BPM systems are introduced. However, the details of the success-critical effects of the cultural aspects remain undisclosed.

Sidorova and Isik (2010) follow a multidisciplinary approach. It is their goal, by means of a text mining technique, to deliver a comprehensive overview of the field of business processes and to identify the central topics of research. This analysis results in a classification of four areas of business process research: design, technologies, implementation, and management. The authors identify the concept of organizational culture as a central issue in the area of implementation. Thus, organizational culture emerges as an important success factor for process initiatives in this paper.

This importance is supported by Sentanin et al. (2008) in their analysis of the implementation of process management in a governmental research center in Brazil. The authors classify their case study within the BPM maturity degree model of Lockamy and McCormack (2004) where the highest level of maturity is characterized by a horizontal, customer-oriented, and collaborative organizational culture. The analysis shows that the predominant organizational culture, also after implementing BPM, still follows traditional functional thinking. Sentanin et al. conclude that a change in the organizational culture is an indispensable demand for the achievement of BPM maturity of an organization. However, the authors do not present empirical evidence for this conclusion.

Cao et al. (2001) argue that in most BPR initiatives, the human and cultural aspects are neglected, leading to an inability to truly integrate the approach in the organization. Hence, related initiatives fail or do not lead to the desired success. Cao et al. follow a holistic perception which includes changes to processes, the company's organizational structure, the organizational culture, and the political positions of power within the company. These four dimensions are not independent, yet, they are to be understood as being related to each other. Thus, change initiatives can only be effective if all four dimensions are taken into account. Accordingly, the authors suggest multiple methods for enabling an integration of change in the whole organization. Cao et al.'s approach is theoretical, however, and is not empirically verified.

Choi and Chan (1997) support this perception and outline success and failure factors in BPR projects. They categorize these factors into three groups: conceptual understanding of the approach, human factors, and skills. Particularly with regard to human factors, the authors emphasize the importance of cultural change for the success of BPR projects. The most frequent causes of failure are identified as a lack of communication and, hence, a lack of motivation towards the project and its results. These points, in turn, lead to a resistance towards the change on the part of employees and management, often in connection with a fear of loss of power or even the job. The authors describe the change in organizational culture as one of the main and most difficult challenges in such projects. According to them, culture is hard to change. Due to this fact, the authors introduce a framework to offer practical assistance to the execution of BPR projects.

Al-Mashari and Zairi (1999) describe BPR as an approach with high potential to increase productivity, quality, and customer satisfaction. Its success, however, depends on certain factors. One of these deals with change management and includes adaptations of the organizational culture. Following this argumentation, the creation of a culture for change is essential for a successful implementation of BPR. As organizational culture is predicated on basic values, it is decisive to explain new values and processes to the organization's employees in order to achieve a common understanding about which new goals are to be pursued and why. The authors enumerate dimensions supporting BPR and point out factors for failure within the respective dimensions. In the dimension of culture, these are: underestimation of the human contribution to BPR initiatives, a failure to consider existing management systems and organizational culture, ignorance of previous values, lack of trust between management and employees, tendencies to imitate other cases, underestimation of the political aspects in such projects, and hostility between differently skilled experts. However, these factors should be seen more as a checklist than a specific model. 
The work of Zucchi and Edwards (1999) offers a detailed survey of human aspects as a success or failure factor in BPR projects. The authors examine the interrelation of BPR and human resource management (HRM), analyze theories of HRM, and group them into four categories: (1) structure and culture, (2) the role of the managers, (3) teamwork, and (4) reward systems. Zucchi and Edwards state that structure and culture in an organization are closely related to each other, and that a change in structure, as required by an orientation towards processes instead of functions, without regard to culture, can be ineffective or even affiliated with negative effects. By means of interviews, the authors analyze the actual execution and implementation of HR theories in practice. The results of their interviews prove that the role of organizational culture is a key element for successful BPR projects.

Ahmad et al. (2007) support this finding. They analyze case studies in three universities in Malaysia that have successfully implemented BPR. All three cases have in common the importance of organizational culture for the success of radical, as well as incremental, change projects. Ahmad et al. particularly underline the fact that a well-developed culture of teamwork supports the achievement of BPR targets.

In Lewis's (2002) paper about the concept of organizational culture, the theoretical interrelation of organizational culture and process-oriented approaches, such as TQM and BPR, is examined. Despite some differences, they all share a common idea: to achieve an improvement in quality and performance it is necessary to either consider the existing organizational culture, or to change the culture in order to realize the desired targets by means of a new organizational culture. In any case, however, organizational culture is a fundamental requirement for increasing quality and achieving management targets and must be seen as a success or failure factor for process-oriented management approaches.

Lee and Dale (1998) carry out an analysis of BPM in a company named as a world market leader in its field. In this case study, an exemplary business unit of the company is analyzed in detail. Within this unit, the intention was to implement BPM. However, the analysis reveals that the cultural change necessary for successful implementation had yet to take place. Within the business unit still exists a strong orientation towards functional responsibilities. Also, the defense of the employees' own competencies is an issue as well as a lack of communication between the different parts of the unit. As one of the main reasons for these difficulties, the authors mention the reward mechanism of the company that, though advancing the competition of the functional areas among each other, retard the cross-functional collaboration in terms of the company's overall objectives. Lee and Dale point out that BPM is not only an instrument for enhancing a company's performance, but also a method to drive the entire organization towards the essential corporate objectives in a process-oriented way. This implies a basic change of the organizational culture, Lee and Dale conclude.

Skrinjar et al. (2008) study the influence of process orientation on companies' performance. Based on the maturity model of process orientation by McCormack and Johnson (2001), they analyze the maturity degree level of an organization and relate it to financial and non-financial performance. According to the maturity degree rating, the authors emphasize the meaning of a change in the organizational culture as an essential aspect with respect to a high maturity degree of process orientation. The paper confirms the strong influence of process orientation, especially on non-financial performance, and indirectly on financial performance. This result supports the idea that organizational culture as a success factor for process management impacts the performance of a company.

The work of Llewellyn and Armistead (2000) deals with the interrelation between social capital and BPM. The authors analyze what informal social networks can contribute at the process level within organizations, using a case study. The theory of social capital postulates that individuals can, according to their personal engagement within a network of relations, access resources which others do not have access to. This theory is confirmed in the study. The three dimensions underlying social capital - structural, relational, and cognitive - are conceptually closely related to organizational culture. One of the authors' conclusions is that effective process management needs an alignment with the culture of an organization in order to support the flow of information and material beyond functional borders. The concept of social capital seems to be interesting - particularly against the background of the still blurry relation between process management and organizational culture.

Da Silva et al. (2012) conduct interviews in two Brazilian service companies to analyze the importance related to BPM tasks and the barriers encountered in the transition from functional management to process-oriented management. The main barrier found in both companies is attached to organizational culture and people because of the existing departmental thinking. The authors state that as a consequence of the stable previous patterns of functional thinking cultural change is very challenging. They suggest a careful management of change supported by BPM training for the employees to promote a focus on processes. 


\subsubsection{Organizational Culture as a Non-Specified Influence}

In addition to the papers covered in the previous section there are four papers mentioning but not specifying the influence of organizational culture on BPM.

Fagan (2006) focuses on three governmental initiatives for the improvement of efficiency and service optimization and shows how BPM can support managers in the public sector. She concludes that BPM can add substantially to process improvement and to an increased orientation towards the needs of citizens, if the particularities of the public sector and the government units are taken into consideration. Fagan mentions a culture of cooperative collaboration, the overcoming of organizational and department-specific reservations, and the creation of new forms of work relations, to be essential for BPM initiatives. This is particularly true in the public sector, as here the function-focused way of thinking is firmly anchored in the conventions and culture of the government. Fagan does not explain the details she draws her conclusions from. Also a detailed description of the cultural influence and its effectiveness is missing.

In a pilot study, Armistead and Machin (1997) carry out interviews and subsequently select four organizations considered as leaders in the field of process management. Based on the data of the pilot study, cognitive maps are created to identify the essential subjects. These subjects are assorted according to six clusters: (1) coordination of the organization beyond internal divisional limits, (2) process description, (3) organizational structure, (4) cultural fitting, (5) amelioration, and (6) rating. The meaning of cultural fitting is described as a central topic, as the performance and results of an organization arise solely from the co-action of people and processes. The authors conclude that the basic BPM approach has to fit into the organizational culture. Changing the organizational culture is, in the long run, not precluded for this reason, but, in contrast to many radical approaches, the existing organizational culture serves as an essential precondition of the BPM initiative. However, there is no detailed description and analysis of the cultural fitting delivered.

Chen (1999) applies the physical laws of thermodynamics to management concepts in order to provide explanations advancing the understanding of the functionality of social systems. Not only is the consideration of purely economic aspects picked out as a central theme, but the dynamics of social relations and organization-cultural aspects are identified as well. Chen suggests that successful management of business processes is, to a high degree, dependant on organization-cultural factors. Thus, he agrees with Martinsons' (1996) point of view, saying that an organizational culture, which is characterized by a high degree of harmony and stability, leads to evolutionary rather than revolutionary changes in respect of control and execution of business processes. However, Chen does not dwell on details of this correlation either.

The interrelation between organizational culture, total quality management (TQM) techniques, and operational performance is examined by Baird et al. (2011). They come to the conclusion that organizational culture is antecedent and influential with respect to TQM techniques. The authors use data from 364 Australian companies within the production and service industries. Organizational culture is surveyed by means of the Organizational Culture Profile (OCP) (O'Reilly et al., 1991). The utilization of TQM techniques is assessed with the help of four main techniques of TQM based on Kaynak (2003): (1) qualitative data and -research, (2) supplier quality management, (3) product and service design, and (4) process management. The contribution appears to be relevant for this literature review, as it considers process management as an important factor even though it is not directly aimed at BPM. The results show that three out of the six organization-cultural dimensions determined by the OCP have a significant positive effect on the extent of the use of TQM techniques. These dimensions are focused on results, teamwork, respect, and innovation. Furthermore, three of the four TQM techniques show a significantly positive effect on the operative profit which indicates an indirect effect of organizational culture on the operative performance. Due to its detailed analysis and the quantitative approach to analyze the interrelation, this survey is particularly interesting. BPM and organizational culture are taken into consideration by means of their conceptual adjacency to the concepts presented in this analysis.

Summarized, the approaches compiled in this section offer interesting insights concerning the influence of organizational culture on BPM. However, they fail to provide a detailed analysis, or substantial proof, of this influence.

\subsection{Influence of BPM on Organizational Culture}

In this section, approaches supporting the perception that process management has an influence on culture in organizations are presented. Contributions supporting this approach regard organizational culture as a component of BPM initiatives. 
Based on a case study, Armistead and Machin (1998) analyze the effects of BPM on the productivity of service companies. The implementation of process orientation is analyzed extensively, using the example of the process of a product pipeline. Armistead and Machin detect that the process approach in this example leads to the implementation of process methods which, in turn, cause a cultural change in the organization as well as an associated change in the attitude and behavior of employees. This would indirectly lead to an increased productivity rate. However, the authors do not respond in depth to the question of how BPM influences organizational culture.

Pritchard and Armistead (1999) explore how process management can be introduced successfully in practice. For this purpose, the authors analyze several European companies that are considered successful in the area of BPM. They find three main results of successful BPM initiatives: (1) improved customer relationships, (2) better cross-functional collaboration within the company, and (3) changes in the organizational culture. The authors argue that employees in companies with explicit experience of BPM implementation also develop a more positive attitude towards BPM and have a more defined idea of the targets and possible use of process management. Furthermore, the companies quite deliberately took company-cultural aspects into consideration in the course of BPM implementation. Thus, Pritchard and Armistead identify the transparency of the vision of the initiative and the communicative attendance of BPM implementation as the main factors that have to be considered in the context of BPM. In addition, they emphasize that it might take some time to enact the paradigm shift that is related to such an initiative, as a process-oriented mindset is frequently in contrast to the commonly accepted and deeply entrenched culture of functional orientation.

Telleria et al. (2002) discover a change of working methods and culture among employees as a constitutive after-effect of BPM in companies. Considerably more teamwork as well as appropriate forms of performance measurement are necessary to manage and motivate employees to change their behavior and performance in a way that corresponds to the new direction of the company. Thus, the authors develop a framework for the performance management of process teams which assists to control employees and processes in such a way that their share in the attainment of company objectives is increased. At the beginning of the study, organizational culture is described as a clear result of BPM. As the paper progresses, it appears to be seen as central factor of success for a BPM initiative. Due to the rather roughly described case study, the interrelation is not clearly explained.

Likewise, Gulledge and Sommer (2002) support the view that organizational culture is influenced by BPM initiatives. Their investigation focuses on the use of process management in the public sector. The authors describe that, predominantly in the public sector, there is a strong focus on function-oriented and hierarchical structures as well as a number of control mechanisms. Such orientation contravenes a process-oriented organizational design. The authors state that when organizations hold on to their vertically oriented communication systems and reward a hierarchically organized way of working there is a high probability that the persons in charge will prevent effective process management. All in all, Gulledge and Sommer (2002) do not offer an optimistic view of BPM in the public sector. The approach is rather descriptive and an empirical proof of the argumentation is not provided.

The empirical work by Sundberg and Sandberg (2006) follows the approach of Gulledge and Sommer (2002) and analyzes process initiatives in the Swedish social insurance administration. By means of quantitative data and qualitative interviews, the survey deals with questions of how functional limits can be overcome, how processes can be coordinated beyond functional limits, and whether radical or incremental change should be aimed at. This survey confirms the assumption that traditional hierarchical structures and control systems are particularly anchored in the public sector and cannot be replaced easily. Thus, it is important to turn special attention to changes in the organizational culture and to break open functional ways of thinking. Hence, the authors conclude that a gradual modus operandi with a goal of an incremental change is an adequate approach in the public sector.

All papers in this section are based on qualitative interviews and are predominantly intuitive, without providing coherent details of the argumentation.

\subsection{Existence of a BPM Culture}

The papers covered in this section rely on the perception that there exists a specific BPM culture in the relationship between BPM and organizational culture. This approach is primarily propagated by authors anchored in the BPM discipline.

Vom Brocke and Sinnl (2011) present a literature review about culture in business process management which proves that culture is a sparsely studied but increasingly important topic in the field of BPM. The authors describe different approaches of the relationship between BPM and culture and separate two definitive elements of the cultural concept: the manifestation of culture on different levels concerning attitude and behavior of employees, and the dimensions of the reference group (national, organizational, and working group). They develop a framework of the role of culture in 
BPM based on the assumption that the management approach of BPM requires a BPM culture. However, the analysis of the direction of influence and effectiveness of the interrelation between culture and BPM is outside of the scope of the framework, as it has been replaced by the newly invented concept of BPM culture. Furthermore, it seems to be critical that vom Brocke and Sinnl only papers from the field of BPM are included in their work - approaches dealing with management and organizational psychology are not taken into consideration although these are the main research fields of organizational culture. With a similar intention, Sidorova and Isik (2010) warn that, due to its cross-disciplinary nature, many literature reviews on topics of BPM fail to cover all relevant aspects.

Likewise, Zairi (1997) pursues the concept of a BPM culture in companies. Following him, BPM requires, amongst others, accredited quality management systems, clear organizational structures, and a strict focus on a company's objectives and strategy as well as the communication of these objectives to all employees. Zairi compares the approaches of global market leaders with a strict BPM orientation in order to deduce rules for the development of a BPM culture. He centers on the importance of the combination of soft and hard aspects of an organizational system. However, he remains abstract with regard to the derivation of the rules which, in the end, constitute a conceptual approach rather than being concrete and implementable.

In sum, the approaches claiming a specific BPM culture address the interrelation between organizational culture and BPM. However, because of their rather abstract nature, they do not appear to be conducive for a deep understanding of the effectiveness of and, consequently, as a management support for the implementation of BPM initiatives.

\section{Core elements of a Research Agenda}

The papers included in this literature review disclose huge differences in the perception regarding the interface between business process management and organizational psychology. The majority of these contributions follow the assumption that organizational culture influences BPM. The antithetic approach regarding the influence of BPM on organizational culture also has several advocates. Few contributions support the existence of a specific BPM culture.

All papers have in common that they identify a definite relation between organizational culture and BPM, and an explicit need to take this relation into account. Nevertheless, the nature of this relation, the questions of why it exists and what its effects actually are, are either ignored or only rudimentarily described. Moreover, the small number of hints delivered in these papers with respect to these questions does not allow a substantive statement to be made. In addition, the works reviewed here are mostly based on qualitative interviews with small numbers of managers from the surveyed companies, or even based on pure estimations. None of the papers included proves a clear, quantitatively constituted interrelation based on manifest key performance measurements of the proposed business processes.

Most papers focus on the BPM point of view and do not clearly elaborate on the concept of organizational culture or relate their assumptions to the conceptual basis of organizational culture. As one consequence of this deficiency, there is no clearly defined common understanding of the concept of organizational culture among the different works as well as no consistent or transparent way of assessing culture in an organization. In sum, the organizational psychological perspective is strongly neglected in the analyzed papers.

Since in many companies there is more than one organizational culture, this issue should also be investigated. Due to mergers and acquisitions or simply due to the geographical distribution of branches (e.g., in one region/country or in multiple regions/countries) or, following the work of vom Brocke and Sinnl (2011), different levels of the respective reference group (e.g., working group or organizational level) subcultures exist. As they may have different impacts on or even cause major challenges for the whole organization (different work conditions, fights for resources, etc.), this issue is highly relevant and should also be further researched.

The literature review reveals that there is a considerable academic gap in the field of the interdependency between organizational culture and BPM. To comply with the demand of the authors that the interrelation should be taken into account when implementing BPM in organizations, it appears indispensable to enhance research with respect to this gap.

To handle the scientific challenge, we suggest a framework based on our literature research. The framework is meant to serve as a basis to better understand the interrelation between the two concepts and provide a basis for upcoming research activities in this area (Figure 3 ). 


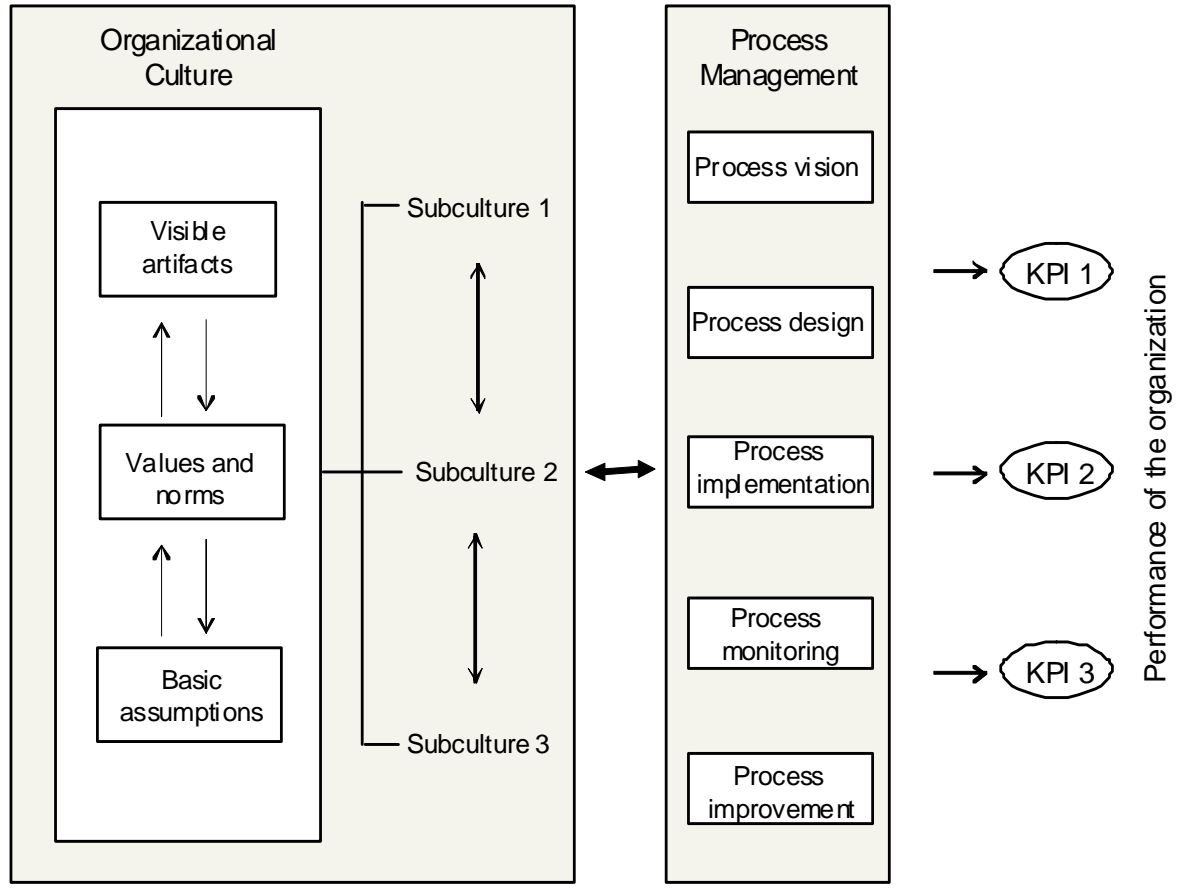

Figure 3. A Framework of the Interrelation between Process Management and Organizational Culture

The analysis of the papers included in this literature review confirms that a relation between BPM and organizational culture exits and that the influence is highly relevant for the organization. Thus, both fields, as well as their relationship, can have both direct and indirect effects on the performance of an organization. Following the organizational culture theory of Schein (1990), we base the concept of organizational culture in our framework on three interrelated levels (basic assumptions, values and norms, and visible artifacts).

In order to positively influence or change the culture of an organization, it is crucial to be aware of these levels and the conceptual mechanisms of their interrelation. In a next step, possible starting points to systematically and fundamentally shape the values and basic assumptions of an organization should be identified.

The different approaches of our literature review reveal that organizational culture is interrelated to process management in a complex and controversially discussed manner regarding the specific mechanisms of influence underlying this interrelation. Besides these influence mechanisms, the interrelation may depend on the respective phase of the BPM life cycle (development of a process vision, process design, process implementation and execution, monitoring, measurement, and evaluation of process performance, and process improvement) of the specific BPM initiative.

The analyzed papers focus on the implementation phase as in this phase a potential discrepancy between the intention of a BPM initiative and the respective organizational culture might become obvious in a hindering behavior of the employees. With regard to a holistic understanding of the interrelation between BPM and organizational culture, it might be important to take the whole BPM life cycle into account, not only the implementation phase. The holistic interrelation is the focal point of interest as it addresses the existing gap in the research.

The relevance of the interrelation becomes obvious, since both BPM and organizational culture influence the overall performance of a company. The influence on the performance occurs and can be measured via a set of key performance indicators (KPIs) based on the company's business processes. By this means, the concrete effects and the dimension of the relevance of the interrelation between process management and organizational culture might be assessed.

The suggested framework reflects all relevant aspects in regard to the interdependency between BPM and organizational culture and their influence on the performance of an organization. It thus provides a substantive basis to deepen the understanding in the respective research areas and serves as an orientation for upcoming research activities. 
Such further research, based on the suggested framework, should address the following issues which thereby constitute a challenging research agenda:

1) Up to now, the existence of a relationship between organizational culture and business process management has only been reckoned in qualitative surveys. A quantitative approach would be helpful to confirm this interrelation and to gain reliable data that allows a comparison to be drawn between different organizational cultures and their respective impacts on the phases of BPM (process vision, process design, process implementation, process measurement, and process improvement).

2) The direction of the influence and the effectiveness of the interrelation have often been discussed. However, both aspects are still of an inconsistent and primarily speculative nature. A detailed analysis of the influence of the two fields on each other is crucial for both further research in this topic and for practice.

3) The existence of several subcultures within an organization and a comparison of their effects on specific KPIs and, thus, on the performance of the company may offer interesting insights into the interdependency between BPM and organizational culture.

4) The exact contact point(s) of the interrelation on the basis of the BPM life cycle has not been analyzed so far. Most of the existing approaches emanate implicitly from an interrelation - which is mainly reflected in the phases of implementation. This assumption, however, is not elaborated on or confirmed in any of the academic papers. Where in the BPM life cycle the interrelation with organizational culture exactly starts, continues, and ends remains another open space for research.

\section{Conclusion}

Organizational culture plays an important role in successfully deploying process management initiatives. Despite an awareness of its importance, the relation of process management and organizational culture has only barely been explored in literature up to now. This paper analyzed and determined the status quo of academic literature from both a process management and an organizational psychological perspective.

For this purpose, we surveyed all papers stemming from both research fields and meeting the requirements as peer-reviewed and having been published in scholarly journals. The literature review classifies the relevant academic works into three categories, including papers dealing with the influence of organizational culture on BPM, the influence of BPM on organizational culture, and the issue of a specific BPM culture.

One result of our literature review is that the coherence of the two fields, process management and organizational culture, has been proven through the analyzed pieces of work. However, no clear statement concerning the details of the interrelation, the causal relation, or even the exact functions of the mechanisms has been delivered until now. Different opinions are delivered but, for the most part, these only rest upon very basic qualitative investigations. Empirical evidence on this topic is still missing. Hence, the literature review reveals a research gap concerning the huge differences in understanding with respect to the interface between BPM and organizational culture. Because of the high relevance of the interrelation for the overall performance of an organization, this gap should be filled by further research. We suggest that the presented framework may serve as a basis for deeper understanding the interdependency between process management and organizational culture.

\section{References}

Ahmad, H., Francis, A., \& Zairi, M. (2007). Business process reengineering: critical success factors in higher education. Business Process Management Journal, 13(3), 451-469. http://dx.doi.org/10.1108/14637150710752344

Al-Mashari, M., \& Zairi, M. (1999). BPR implementation process: an analysis of key success and failure factors. Business Process Management Journal, 5(1), 87-112. http://dx.doi.org/10.1108/14637159910249108

Al-Mashari, M., \& Zairi, M. (2000). Revisiting BPR: a holistic review of practice and development. Business Process Management Journal, 6(1), 10-42. http://dx.doi.org/10.1108/14637150010283045

Armistead, C., \& Machin, S. (1997). Implications of business process management for operations management. International Journal of Operations \& Production Management, 17(9), 886-898. http://dx.doi.org/10.1108/01443579710171217

Armistead, C., \& Machin, S. (1998). Business process management: implications for productivity in multi-stage 
service networks. International Journal of Service Industry Management, 9(4), 323-336. http://dx.doi.org/10.1108/09564239810228849

Armistead, C., Pritchard, J.-P., \& Machin, S. (1999). Strategic business process management for organizational effectiveness. Long Range Planning, 32(1), 96-106. http://dx.doi.org/10.1016/S0024-6301(98)00130-7

Baird, K., Hu, K.J., \& Reeve, R. (2011). The relationships between organizational culture, total quality management practices and operational performance. International Journal of Operations \& Production Management, 31(7), 789-814. http://dx.doi.org/10.1108/01443571111144850

Becker, J., \& Kahn, D. (2011). The Process in Focus. In J. Becker, M. Kugeler, \& M. Rosemann (Eds.), Process Management - A Guide for the Design of Business Processes (2nd ed.) (pp. 1-12). Berlin, Germany: Springer. http://dx.doi.org/10.1007/978-3-540-24798-2_1

Beugelsdijk, S., Koen, C.I., \& Nooderhaven, N.G. (2006). Organizational culture and relationship skills. Organization Studies, 27(6), 833-854. http://dx.doi.org/10.1177/0170840606064099

Cameron, K.S., \& Quinn, R.E. (1999). Diagnosing and changing organizational culture based on competing values framework. Reading, MA: Addison Wesley.

Cao, G., Clarke, S., \& Lehaney, B. (2001). A critique of BPR from a holistic perspective. Business Process Management Journal, 7(4), 332-339. http://dx.doi.org/10.1108/EUM0000000005732

Chen, W.-H. (1999). Business Process Management: a thermodynamics perspective. Journal of Applied Management Studies, 8(2), 241-257.

Choi, C.F., \& Chan, S.L. (1997). Business process re-engineering: evocation, elucidation and exploration. Business Process Management Journal, 3(1), 39-63. http://dx.doi.org/10.1108/14637159710161576

Da Silva, L.A., Damian, I.P.M., \& de Pádua, S.I.D. (2012). Process management tasks and barriers: functional to process approach. Business Process Management Journal, 18(5), 762-776. http://dx.doi.org/10.1108/14637151211270144

Davenport, T.H. (1993). Process innovation - Reengineering Work through information technology. Boston, MA: Harvard Business School Press.

Davenport, T.H., \& Short, J.E. (1990). The New Industrial Engineering: Information Technology and Business Process Redesign. Sloan Management Review, 31(4), 11-27.

Dumas, M., La Rosa, M., Mendling, J., \& Reijers, H.A. (2013). Fundamentals of Business Process Management. Berlin, Germany: Springer. http://dx.doi.org/10.1007/978-3-642-33143-5

Fagan, M.H. (2006). Exploring city, county and state e-government initiatives: an East Texas perspective. Business Process Management Journal, 12(1), 101-112. http://dx.doi.org/10.1108/14637150610643797

Gulledge Jr, T.R., \& Sommer, R.A. (2002). Business process management: public sector implications. Business Process Management Journal, 8(4), 364-376.

Hammer, M. (1990). Re-engineering Work: Don't Automate, Obliterate. Harvard Business Review, 68(4), 104-112.

Hammer, M., \& Champy, J. (1993). Reengineering the Cooperation. A Manifesto for Business Revolution. New York, NY: Harper Business.

Harmon, P. (2007). Business Process Change (2nd ed.). Burlington, MA: Morgan Kaufmann. http://dx.doi.org/10.1016/B978-0-12-374152-3.50072-0

Hofstede, G. (1980). Culture's Consequences: International Differences in Work-Related Values. Beverly Hills, CA: Sage.

Hofstede, G. (1991). Cultures and Organizations. London, England: McGraw-Hill. http://dx.doi.org/10.1080/09585192.2011.561217

Houy, C., Fettke, P., \& Loos, P. (2010). Empirical research in business process management - analysis of an emerging field of research. Business Process Management Journal, 16(4), 617-661. http://dx.doi.org/10.1108/14637151011065946

Jeston, J., \& Nelis, J. (2008). Business Process Management (2nd ed.). Burlington, MA: Butterworth-Heinemann. http://dx.doi.org/10.1016/B978-0-7506-8761-4.00010-X

Kannengiesser, U. (2008). Subsuming the BPM life cycle in an ontological framework of designing. In J.L.G. Dietz, 
A. Antonia, \& J. Barjis (Eds.), 4th International Workshop CIAO! and 4th International Workshop EOMAS, Berlin, Germany: Springer, pp. 31-45. http://dx.doi.org/10.1007/978-3-540-68644-6_3

Kaynak, H. (2003). The relationship between total quality management practices and their effects on firm performance. Journal of Operations Management, 21(4), 405-435. http://dx.doi.org/10.1016/S0272-6963(03)00004-4

Keesing, R.M. (1974). Theories of Culture. Annual Review of Anthropology, 3, 73-97. http://dx.doi.org/10.1146/annurev.an.03.100174.000445

Kitchenham, B. (2004). Procedures for performing systematic reviews. Joint Technical Report, Software Engineering Group, Department of Computer Science, Keele University, Keele, England.

Knapp, E.M. (1998). Knowledge management. Business Economic Review, 44(4), 3-6.

Kohlbacher, M. (2010). The effects of process orientation: a literature review. Business Process Management Journal, 16(1), 135-152. http://dx.doi.org/10.1108/14637151011017985

Kohlbacher, M., \& Gruenwald, S. (2011). Process orientation: conceptualization and measurement. Business Process Management Journal, 17(2), 267-283. http://dx.doi.org/10.1108/14637151111122347

Lederer Antonucci, Y., \& Goeke, R.J. (2011). Identification of appropriate responsibilities and positions for business process management success: Seeking a valid and reliable framework. Business Process Management Journal, 17(1), 127-146.

Lee, R.G., \& Dale, B.G. (1998). Business process management: a review and evaluation. Business Process Management Journal, 4(3), 214-225. http://dx.doi.org/10.1108/14637159810224322

Lewis, D. (2002). Five years on - the organizational culture saga revisited. Leadership \& Organization Development Journal, 23(5), 280-287. http://dx.doi.org/10.1108/01437730210435992

Leyer, M. (2011). Stand der Literatur zur operativen Steuerung von Dienstleistungsprozessen. Frankfurt School Working Paper Series, No. 170, Frankfurt a.M., Germany.

Llewellyn, N., \& Armistead, C. (2000). Business process management - Exploring social capital within processes. International Journal of Service Industry Management, 11(3), 225-243. http://dx.doi.org/10.1108/09564230010340751

Lockamy, A. III, \& McCormack, K. (2004). The development of a supply chain management process maturity model using the concepts of business process orientation. Supply Chain Management: An International Journal, 9(4), 272-278.

Martinsons, M.G. (1996). Cultural constraints on radical re-engineering: Hammer and Lewin meet Confucius. Journal of Applied Management Studies, 5(1), 85-96.

Mead, G.H. (1934). Mind, Self, and Society. Chicago, IL: University of Chicago Press. http://dx.doi.org/10.7208/chicago/9780226516608.001.0001

Nordsieck, F. (1934). Grundlagen der Organisationslehre (2nd ed.). Stuttgart, Germany: Poeschel.

Obenchain, A. (2002). Organizational culture and organizational innovation in not-for-profit, private and public institutions of higher education. UMI: unpublished dissertation, Nova Southeastern University, Davie, FL.

Ogbonna, E., \& Harris, L.C. (2000). Leadership style, organizational culture and performance: empirical evidence from UK companies. International Journal of Human Resource Management, 11(4), 766-88. http://dx.doi.org/10.1080/09585190050075114

Okoli, C., \& Schabram, K. (2010). A Guide to Conducting a Systematic Literature Review of Information Systems Research. Sprouts: Working Papers on Information Systems, 10(26). 10-26. http://dx.doi.org/10.2139/ssrn.1954824

O’Reilly, C.A., Chatman, J., \& Caldwell, D.F. (1991). People and organizational culture: a profile comparison approach to assessing person-organizational fit. Academy of Management Journal, 34(3), 487-516. http://dx.doi.org/10.2307/256404

Osterloh, M., \& Frost, J. (2006). Prozessmanagement als Kernkompetenz - Wie Sie Business Reengineering strategisch nutzen können (5th ed.). Wiesbaden, Germany: Gabler.

Palmberg, K., (2010). Experiences of implementing process management: a multiple-case study. Business Process 
Management Journal, 16(1), 93-113. http://dx.doi.org/10.1108/14637151011017967

Prätorius, G., \& Tiebler, P. (1993). Ökonomische Literatur zum Thema Unternehmenskultur. In M. Dierkes, L. von Rosenstiel, \& U. Steger (Eds.), Unternehmenskultur in Theorie und Praxis: Konzepte aus Ökonomie, Psychologie und Ethnologie (pp. 23-89). Frankfurt a.M., Germany: Campus.

Pritchard, J.-P., \& Armistead, C. (1999). Business process management - lessons from European business. Business Process Management Journal, 5(1), 10-32. http://dx.doi.org/10.1108/14637159910249144

Ravesteyn, P., \& Batenburg, R. (2010). Surveying the critical success factors of BPM-systems implementation. Business Process Management Journal, 16(3), 492-507. http://dx.doi.org/10.1108/14637151011049467

Rosemann, M., \& vom Brocke, J. (2010). The six core elements of business process management. In J. vom Brocke, \& M. Rosemann (Eds.), Handbook on Business Process Management: Introduction, Methods and Information Systems, 1 (pp. 109-124). Berlin, Germany: Springer. http://dx.doi.org/10.1007/978-3-642-00416-2_5

Schein, E.H. (1978). Career Dynamics. Reading, MA: Addison-Wesley.

Schein, E.H. (1990). Organizational Culture. American Psychologist, 45(2), 109-119. http://dx.doi.org/10.1037//0003-066X.45.2.109

Schein, E.H. (1995). Unternehmenskultur. Ein Handbuch für Führungskräfte. Frankfurt a.M., Germany: Campus.

Schmelzer, H.J., \& Sesselmann, W. (2008). Geschäftsprozessmanagement in der Praxis. Kunden zufriedenstellen, Produktivität steigern, Wert erhöhen. Munich, Germany: Hanser.

Sentanin, O.F., Fernando, C.A.S., \& Jabbour, C.J.C. (2008). Business process management in a Brazilian public research centre. Business Process Management Journal, 14(4), 483-496. http://dx.doi.org/10.1108/14637150810888037

Sidorova, A., \& Isik, O. (2010). Business process research: a cross-disciplinary review. Business Process Management Journal, 16(4), 566-597. http://dx.doi.org/10.1108/14637151011065928

Skrinjar, R., Bosilj-Vuksic, V., \& Indihar-Stemberger, M. (2008). The impact of business process orientation on financial and non-financial performance. Business Process Management Journal, 14(5), 738-754. http://dx.doi.org/10.1108/14637150810903084

Sundberg, H.P., \& Sandberg, K.W. (2006). Towards e-government: a survey of problems in organisational processes. Business Process Management Journal, 12(2), 149-161. http://dx.doi.org/10.1108/14637150610657503

Telleria, K.M., Little, D., \& MacBryde, J. (2002). Managing process through teamwork. Business Process Management Journal, 8(4), 338-350. http://dx.doi.org/10.1108/14637150210434991

van der Aalst, W.M.P., Hofstede, A.H.M., \& Weske, M. (2003). Business process management: a survey. In W.M.P. van der Aalst, A.H.M. ter Hofstede, \& M. Weske (Eds.), International Conference on Business Process Management 2003 (pp. 1-12) Berlin, Germany: Springer. http://dx.doi.org/10.1155/2013/507984

vom Brocke, J., \& Schmiedel, T. (2011). Towards a Conceptualisation of BPM Culture: Results from a Literature Review. 15th Pacific Asia Conference on Information Systems (PACIS), Brisbane, Australia.

vom Brocke, J., \& Sinnl. T. (2011). Culture in business process management: a literature review. Business Process Management Journal, 17(2), 357-377. http://dx.doi.org/10.1108/14637151111122383

Voss, C.A., \& Huxham, C. (2004). Problems, dilemmas and promising practice. Proceedings of the 11th Annual EurOMA Conference, Paris, France (pp. 309-318).

Weber, M. (1930). The Protestant Ethic and the Spirit of Capitalism. Translated by Talcott Parsons. New York, NY: Scribners.

Weske, M. (2007). Business Process Management: Concepts, Languages, Architectures. Berlin, Germany: Springer.

Zairi, M. (1997). Business process management: a boundaryless approach to modern competitiveness. Business Process Management Journal, 3(1), 64-80. http://dx.doi.org/10.1108/14637159710161585

Zucchi, F., \& Edwards, J.S. (1999). Human resource management aspects of business process management: a survey. Business Process Management Journal, 5(4), 325-344. http://dx.doi.org/10.1108/14637159910297376 
Appendix 1. Analyzed peer-reviewed journals

\begin{tabular}{|c|c|}
\hline Journal title & Publication period \\
\hline Business Process Management Journal (BPMJ) & 1995 to $12 / 2012$ \\
\hline Culture and Organization & 1995 to $12 / 2012$ \\
\hline Economics and Organization of Enterprise & 2008 to 2010 \\
\hline Emergence: Complexity and Organization (E:CO) & 1999 to $12 / 2012$ \\
\hline European Journal of Operational Research (EJOR) & 1977 to $12 / 2012$ \\
\hline Group \& Organization Management (GOM) & 1976 to $12 / 2012$ \\
\hline Human Organization (HO) & 1941 to $12 / 2012$ \\
\hline Information and Organization & 1991 to $12 / 2012$ \\
\hline International Journal of Advanced Operations Management (IJAOM) & 2009 to $12 / 2012$ \\
\hline International Journal of Business Process Integration and Management & 2005 to $12 / 2012$ \\
\hline International Journal of Operations \& Production Management (IJOPM) & 1980 to $12 / 2012$ \\
\hline International Journal of Service Science, Management, Engineering, and Technology & 2010 to $12 / 2012$ \\
\hline International Journal of Services and Operations Management (IJSOM) & 2005 to $12 / 2012$ \\
\hline International Journal of Industrial Organization (IJIO) & 1983 to $12 / 2012$ \\
\hline International Journal of Operational Research (IJOR) & 2005 to $12 / 2012$ \\
\hline International Journal of Organization Theory and Behavior (IJOTB) & 1998 to $12 / 2012$ \\
\hline International Organization (IO) & 1947 to $12 / 2012$ \\
\hline International Studies of Management \& Organization & 1971 to $12 / 2012$ \\
\hline Journal of Applied Management Studies & 1996 to $12 / 2000$ \\
\hline Journal of Economic Behavior \& Organization & 1980 to $12 / 2012$ \\
\hline Journal of Information and Operations Management & 2011 to $12 / 2012$ \\
\hline Journal of Management and Organization (JMO) & 1995 to $12 / 2012$ \\
\hline Journal of Operations Management (JOM) & 1980 to $12 / 2012$ \\
\hline Journal of Organizational Culture, Communications and Conflict & 2006 to $12 / 2012$ \\
\hline Journal of Service Management (JSM) & 1990 to $12 / 2012$ \\
\hline Journal of Service Science and Management (JSSM) & 2008 to $12 / 2012$ \\
\hline Leadership \& Organization Development Journal, The & 1980 to $12 / 2012$ \\
\hline Learning Organization, The & 1994 to $12 / 2012$ \\
\hline Manufacturing \& Service Operations Management (M\&SOM) & 1999 to $12 / 2012$ \\
\hline Operations Research (OR) & 1984 to $12 / 2012$ \\
\hline Organization & 1994 to $12 / 2012$ \\
\hline Organization Science & 1990 to $12 / 2012$ \\
\hline Organization Studies & 1980 to $12 / 2012$ \\
\hline Production and Operations Management (P\&OM) & 1999 to $12 / 2012$ \\
\hline Strategic Organization & 2003 to $12 / 2012$ \\
\hline
\end{tabular}

